\title{
Violencia, transgresión y bienes comunes en Copiapó (siglos XVII y XVIII)*
}

\section{Violence, Transgression and Common Goods in Copiapo (17th and I8th Centuries)}

\author{
Inmaculada Simón Ruiz**
}

Instituto de Estudios Sociales y Humanísticos Universidad Autónoma de Chile, Santiago, Chile http://orcid.org/oooo-000I-5820-2930

\begin{abstract}
Raúl Sánchez Andaur***
Instituto de Estudios Sociales y Humanísticos Universidad Autónoma de Chile, Santiago, Chile http://orcid.org/0000-0003-450I-2702

ISSN: ISSN-OI85-4259; e-ISSN: 2007-9I76

DOI: http://dx.doi.org/I0.28928/revistaiztapalapa/8520I8/atcI/simonruizi/sanchezandaurr
\end{abstract}

\begin{abstract}
Resumen
Presentamos un análisis de conflictividad en torno al acceso a recursos comunes en el Valle de Copiapó en los siglos xvir y xviri. En ese período se produjo la ocupación por parte de los españoles de territorios indígenas. Sus antiguos pobladores perdieron, con ello, el acceso a lugares de extracción de recursos como la brea, la madera o el agua. Analizamos aquí tres casos en los que se percibe incumplimiento de las relaciones establecidas en torno a los usos de los bienes comunes, tomando como instrumento de análisis los principios de diseño establecidos por Elinor Ostrom en la organización de instituciones exitosas en la gestión de recursos comunes a lo largo de la historia.
\end{abstract}

Palabras claveः Agua, bosques, brea, conflictividad.

\begin{abstract}
We present an analysis of the conflicts based on the access to common resources in the Copiapó Valley in the I7th and I8th centuries. During that period the Spaniards occupied indigenous territories, and, as a result, its native inhabitants lost the access to places of extraction of resources such as pitch, wood or water. This article studies three cases where the established relations around the uses of the common goods was not met. As a method of analysis, the article is based on the design principles established by Elinor Ostrom in the management of common resources in the organization of successful institutions throughout the history.
\end{abstract}

Keywords: Water, forests, pitch, conflict.

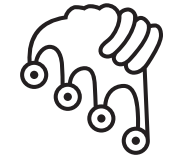

\section{IZTAPALAPA}

Agua sobre lajas

* Esta investigación se llevó a cabo gracias al apoyo de los proyectos de investigación interna de la Universidad Autónoma de Chile: DIUA I04-20I7 y DIP83-I6. Agradecemos a Guillermo Cortés Lutz y Rodrigo Zalaquett su gentileza durante la estadía realizada en el Museo Regional de Atacama y a Jimena Ferreiro el apoyo en el Archivo Histórico del mismo.

** isruiz72@gmail.com

*** rsancheza@uautonoma.cl 


\section{Introducción}

bordar la temática que proponemos ha sido complejo dado que la informa-
ción sobre el Valle de Copiapó para la época que nos preocupa se encuentra
dispersa e incompleta. No ha sido posible localizar las actas del cabildo, ya que el Archivo Municipal solo contiene documentación a partir de 1836, cuando Copiapó se desvincula de La Serena y pasa a ser capital provincial a causa de los cambios ocurridos tras el descubrimiento del mineral de plata de Chañarcillo. En el archivo del Museo Regional de Atacama encontramos fuentes relativas a Intendencia, pero en su mayoría para la segunda mitad del xix.

La escasez de fuentes dificulta conocer en profundidad el funcionamiento de las relaciones económicas, sociales y políticas en el Valle. A pesar de eso, para el tema de la conflictividad en torno al uso de los bienes comunes, contamos con otros repositorios como los archivos judiciales y la información que llegaba a la Real Audiencia. En esos repositorios hemos localizado varios expedientes relativos a dichos conflictos, algunos de los cuales ya han sido analizados por otros investigadores que han trabajado sobre Copiapó en el siglo xviII (Torres Sánchez, 1985; Broll, 1988). Otro autor que desarrolló una investigación sobre esta región es Sayago (I874); si bien su libro presenta información muy valiosa tomada de los archivos, no dejó testimonio de la ubicación de las fuentes consultadas. Sin embargo, su obra es de consulta obligada porque presenta una panorámica única de la historia del Valle de Copiapó.

Otras fuentes de información las encontramos en la "Matrícula de los habitantes de Copiapó y su jurisdicción, con fecha de 4 de enero de I745"; en el "Informe de Don Francisco Cortés al Gobernador J. Manso de Velasco" y en la documentación relativa a la fundación de la Villa de San Francisco de Copiapó, todas ellas recopiladas en Fuentes para la historia urbana del Reino de Chile por la Academia Chilena de la Historia (Lorenzo, 1995). Para la legislación contamos con la Recopilación de las Leyes de los Reynos de las Indias (Carlos II,I68I) y con el Boletin Municipal del Departamento de Copiapó (187I). 
A partir de la documentación, analizaremos la conflictividad en torno al acceso a la brea, la madera y el agua. Se trata de elementos muy vinculados a la tierra y la naturaleza, de los que la población del Valle venía haciendo uso desde antiguo (hasta que la llegada de los españoles en el siglo xvi obstaculizó el acceso a dichos recursos), a través de la puesta en práctica de distintas formas de explotación, y colaboró con la ruptura del equilibrio que existía antes del proceso de conquista y colonización.

Para analizar la gestión de los recursos en el Valle nos basaremos en Elinor Ostrom y en sus "principios de diseño característicos de instituciones de larga duración de los Recursos de Uso Común (RUC)" (Ostrom, 20II: 165) que enumeramos en la siguiente tabla. Todo ello con el objetivo de establecer si en el Valle de Copiapó, durante los siglos XVII y XVIII, los instrumentos y mecanismos diseñados para gestionar los recursos con el fin de evitar o solucionar los conflictos, fueron suficientes y, en su defecto, para comprobar por qué no hubo una correlación exitosa como en la de los casos analizados por Ostrom.

\section{TABLA I.}

Principios de diseño característicos de instituciones de larga duración de los RUC

I.- Existencia de unos límites claramente definidos

2.- Coherencia entre las reglas de apropiación y provisión con las condiciones locales

3.- Arreglos de elección colectiva

4.- Monitoreo

5.- Sanciones graduadas

6.- Mecanismos para la resolución de conflictos

7.- Reconocimiento mínimo de derechos de organización

8.- Las actividades de apropiación, provisión, supervisión, aplicación de las normas, resolución de conflictos y gestión se organizan en múltiples niveles de instituciones anidadas (de distinto nivel)

A partir del análisis de diversos modelos de gestión de recursos comunes a nivel mundial, Ostrom encuentra que hay una serie de características que comparten los casos que han sido exitosos en la larga duración; esto es, que han evitado los conflictos o que han sido eficaces en su resolución cuando se han producido. Estos "principios de diseño" son aplicados de manera diversa de acuerdo con los contextos 
y las reglas particulares en cada uno de los casos en que se aplican (una aldea suiza, la huerta valenciana, comunidades de riego en Filipinas y unas aldeas en Japón). Se trata de una serie de casos paradigmáticos que, en contextos muy diversos, son exitosos, y que involucran recursos similares a los aquí presentados. Por ello, consideramos pertinente analizar el uso de recursos comunes en un valle relativamente aislado en el norte chileno durante los siglos XVII y xviII a partir de estos principios, con el fin de entender por qué no fueron igualmente exitosos si la legislación indiana los amparaba (Carlos II, I68I $)^{1}$ y, además, existía una larga experiencia en el uso comunitario de recursos previa a la Conquista.

Comenzaremos presentando las características geográficas principales del Valle de Copiapó, así como una breve descripción de los principales actores involucrados en los conflictos. A continuación, analizaremos los tres casos de estudio para dar paso, finalmente, a la aplicación de los enunciados de Ostrom con el fin de responder a la pregunta principal de la investigación.

\section{El Valle de Copiapó}

Situado en el Norte de Chile en un espacio intermedio entre la zona desértica del Norte Grande y la zona central, el Valle de Copiapó, durante la ocupación española, constituyó el límite entre el reino de Chile y el despoblado de Atacama. Su mayor interés para los conquistadores estuvo en sus recursos mineros.

El valle se encuentra atravesado por el Río Copiapó, un curso de agua cordillerano andino que se forma a I,230 metros de altura sobre el nivel del mar y que recibe las aguas del Jorquera, el Pulido, el Manflas y de la quebrada de Paipote. Culmina su recorrido de $160 \mathrm{~km}$ en la localidad de Puerto Viejo. Las aguas de estas fuentes hídricas provienen del deshielo de la nieve que cae en la cordillera y no de la lluvia, que cae cada dos o tres años y se pierde en sus más de $160 \mathrm{~km}$, de manera que, como señalaba Darwin en I835, en treinta años no había llevado una gota de agua hasta el mar (Darwin, 20II: 6I) ${ }^{2}$

1 Sobre todo, se contempla en el Libro vi, Título iv, donde se hace referencia a la gestión y uso de los bienes de las comunidades.

2 El texto aquí referenciado es una publicación en la que se recoge el capítulo xvi del libro Viaje de un naturalista alrededor del mundo en donde narra su experiencia en el Norte de Chile en 1835 . 
El paisaje del Valle es el de un desierto semiárido. Si bien la vegetación existente era más abundante que en la actualidad, hay que tomar con reservas las afirmaciones de que se trataba de una región boscosa antes de la llegada de la minería. Según señala Camus (2004:290), estas opiniones vienen de las vertidas por Sayago en la década de los setenta del siglo xix, momento en que había una gran pugna entre agricultores y mineros, los primeros acusaban a los segundos de ser culpables de la deforestación de la región. Camus señala que, efectivamente, existían algunas zonas boscosas en torno a las quebradas pero que, en general, la madera escaseaba en el valle en el momento de la fundación de la villa, y que las mejores tierras se encontraban despejadas y habilitadas para la agricultura.

El área corresponde a la zona de ocupación de la cultura Copayapu, que a partir del I470 fue anexada al Tawantinsuyu, donde el Inca envió grupos de mitimaes desde los valles de Elqui y Huasco. A partir del curso alto hacia la desembocadura podemos señalar una divisoria cuando el río recibe las aguas de la quebrada de Paipote, quedando a un lado las mejores tierras y el mayor número de minas. En la parte más cercana a la cordillera se encuentra el Valle de Camasquil, donde se ubicaron a la llegada de los españoles dos grandes propiedades: Potrero Grande y Potrero Seco, ambas dedicadas primordialmente a la minería, la segunda se constituyó como un gran centro de amalgamación en el antiguo pueblo de Camasquil (Sayago, 1874: 12). Más abajo, se encontraban el Plomo, las poblaciones de Tierra Amarilla y Nantoco, donde el pueblo de Copapayu había tenido su principal asentamiento en los terrenos que en parte constituyen lo que se conoce como La Chimba, y que pasó a propiedad del conquistador Francisco de Aguirre, cuyo hijo Hernando levantó el primer trapiche en la zona, y otro más abajo conocido como Totoralillo.

Al otro lado de la quebrada de Paipote se localizaban la Viñita y algunas haciendas importantes, como Ramadilla y Bodega, también conocida como La Marquesa (ambas en tierras que habían pertenecido al cacique don Francisco Guanitai) y Chamonante, que se originó en la merced provista en 1652 al capitán Juan Cisternas Escobar.

Las principales actividades de estas propiedades fueron la minería y la agricultura, practicada tanto por las grandes haciendas como por las poblaciones al interior de las mismas y en los alrededores. Existía, además, una actividad importante en torno a la ganadería. Pero es relevante señalar que tanto la agricultura como la ganadería se realizaban en gran medida para el abastecimiento de la minería.

En el siglo xvin se establecieron dos núcleos de población: el Pueblo de Indios de San Fernando, en 1725, y la Villa de San Francisco de la Selva de Copiapó, en 1744. 


\section{El acceso a la recolección de brea en el siglo XVI}

La conquista, sobre todo la implantación de los sistemas de mita y encomienda, generó una disminución importante de la población autóctona, la cual se levantó en contra del primer encomendero, Juan Bohón, que fue ahorcado en I549 en una revuelta que llevó a los indios hasta La Serena pero que terminó siendo sofocada, finalmente, por los españoles. La recuperación del Valle por parte de los españoles supuso una nueva crisis para los indios, que lentamente fueron replegándose y adaptándose a las nuevas circunstancias sin dejar, por ello, de presentar resistencias. Entre las actividades económicas de los indios de Copayapu se encontraban la agricultura, la ganadería y la extracción de brea. Esta última se explotaba con diversas finalidades entre las que se encontraba el uso medicinal de la sicha, un parásito que crece sobre ella, y que también se utilizaba para la fabricación de harina ceremonial (Villagrán y Castro, 2003: 139-I40). El aprovechamiento de la brea no quedaba ahí, la población autóctona había sabido sacar gran utilidad a uno de los escasos recursos que la aridez del clima no impedía que se diera de forma continuada. Entre los usos más antiguos se encuentra el de la construcción, pero también era útil para la fabricación de utensilios de cerámica y como forraje de ganado, así como para el calafateo de barcos y toneles para guardar el agua de bebida, vino y aguardiente, por lo cual era un valioso artículo de intercambio comercial.

Según Sayago la explotación de brea en el siglo xvir por parte de los indios fue una fuente de ingresos suficiente como para permitirles vestirse y también pagar tributo y doctrina al encomendero. No obstante, su recolección se había visto mermada porque los muleros, a su paso a través de la cordillera, llevaban al ganado a pastar sin pagar nada a los indios por ello. Ante esta situación, el cacique Alonso Tacquia, llevó el caso a la Real Audiencia que dictó a su favor un auto el I7 de agosto de I643 por medio del cual autorizaba al curador de los indios a cobrar por el uso de los bredales al tiempo que prohibía expresamente a los corregidores que se adueñaran del producto bajo pena de 500 pesos (Sayago, 1874: 247). Lamentablemente, después de esto, los corregidores tomaron conciencia de las posibilidades de negocio y se apoderaron de él obligando a los indios a convertirse en meros recolectores. Los corregidores procedían después a venderla al encomendero Juan Cisternas que poseía grandes extensiones de tierra en el lugar denominado Potrero Grande.

Así continuaron las cosas hasta que hubo una importante riada en el año 1655 que arrasó los bredales de Nantoco y los indios tuvieron que buscar un nuevo lugar para su recolección. Paradójicamente, las mismas lluvias que provocaron la riada 
convirtieron en zona muy apta para la brea a las tierras de Potrero Grande, que a partir de entonces denominaron el Potrero de la Brea (Sayago, 1874: 12).

Los indios solicitaron autorización para acceder a las tierras de Potrero Grande y explotar la brea, ya que, de acuerdo con sus alegatos, la propiedad se ubicaba en antiguas tierras indígenas. El problema era que para entonces el paraje estaba ocupado por todo tipo de ganado (vacas, ovejas, cerdos y las mulas que iban a Potosí) que pertenecían al encomendero Juan Cisternas. Este se negó a permitir la entrada de los indios, quienes se querellaron contra él. Después de un largo juicio, los indios encontraron justicia en 1677, luego de veinte años, cuando el corregidor Fernando de Aguirre Riveros ordenó evacuar a todos los animales que pastaban en el bredal de Potrero Grande, y que el acceso de los indios fuera expedito para la recolección en dichas tierras ${ }^{3}$.

La victoria fue provisional, pues Cisternas apeló ante lo que él consideraba como un despojo en la Real Audiencia y salió vencedor en I684. Este nuevo escenario dejó a los indios sin acceso a la explotación comunal del potrero y, con ello, a una importante fuente de ingresos y a un producto primordial para la práctica de la medicina y de los rituales sagrados tradicionales. Así, el despojo a los indios iniciado por los corregidores fue continuado por los encomenderos. La brea se siguió cosechando, pero ya no por parte de los antiguos pobladores del Valle sino por el encomendero Juan Cisternas en sus propiedades de Potrero Grande y Chamonate con fines comerciales y para la alimentación del ganado. El recurso se convirtió en una importante fuente de ingresos y en el siglo XVIII aparece en varias ocasiones incluida como dote de las hijas de familia (Sayago, 1874: 249). En este proceso, Cisternas y sus herederos lograron no solo los derechos sobre Potrero Grande sino también el acceso libre a un recurso que antes se obtenía únicamente de manera controlada a partir del tributo pagado por los indios en encomienda.

La intermediación inicial de la Corona, fue insuficiente en cuanto no se hicieron valer los derechos de los pobladores originarios. En este caso, como en muchos otros, su actuación paternalista con los indígenas garantizó una mirada proteccionista con la única pretensión de que contaran con los mínimos recursos de subsistencia y pudiesen continuar con el servicio a los intereses de la Corona. Se legisló a su favor, pero cuando el conflicto llegó a la Real Audiencia prevaleció el interés de los encomenderos.

3 Archivo Nacional Histórico (en adelante AHN), Notarios de Copiapó, vol.I. 


\section{El acceso a la madera para la fundación de la Villa de San Fran- cisco de la Selva de Copiapó}

Años más tarde, un caso similar de cerramiento volvió a involucrar como uno de sus principales protagonistas a Potrero Grande, si bien esta vez los perjudicados no son solo los indios sino los nuevos pobladores de la Villa. En I744 Manso de Velasco nombraba a Francisco Cortés superintendente de la jurisdicción de Copiapó, y le encargaba la fundación de una villa de españoles en un terreno "a propósito". El gobernador recomendó que se eligiera una ubicación en que hubiera alguna población congregada, así como conventos e iglesia parroquial, y le otorgó facultades a Cortés para hacer mensura y reparto de tierras bajo el supuesto de que podía "haber muchas tierras y potreros vacantes, así por muerte y falta de indios, como por detenerlas y tenerlas usurpadas algunos de aquellos hacendados" (Lorenzo, 1995: 280).

Cortés quedó encargado, por tanto, de revisar los lindes de las propiedades de los hacendados y también de los religiosos (en las inmediaciones se encontraba el convento de los mercedarios) y particulares, así como de los indios, para la ubicación de la villa y posterior reparto de mercedes de tierras. El lugar seleccionado fue, finalmente, el pueblo de Copiapó que pasaría a denominarse San Francisco de la Selva de Copiapó.

De poco servía otorgar tierras a los futuros habitantes de la villa si no se les proporcionaba agua para regarlas y por ello, el 29 de agosto de 1744, Manso de Velasco ordenaba expresamente:

(...) que respecto de experimentarse alguna escasez de agua en el río, a causa de usar de ella los hacendados y trapicheros sin orden reglado; que lo dé y haga repartimiento de ella, señalando a cada uno lo que precisamente necesite según el número de tierras y su calidad, obligándoles a todos a que pongan marco, y a los trapicheros que tienen sus trapiches en lo superior de la población a que vuelvan las aguas a la madre principal del rio porque no se pierdan inútilmente (Lorenzo, 1995: 283).

Dada la despoblación de la zona por huida o muerte de los indios, se señalaba la necesidad de hacer recuento de los indios de encomienda y libres para dar prioridad a su contratación en las labores de construcción de edificios públicos y viviendas en la Villa "pagándoles su justo trabajo en la cuota y modo que allí fuere de estilo, sin permitir que sean vejados ni molestados" (Lorenzo, 1995: 284). Para ello se levantó la Matrícula de los habitantes de Copiapó y su jurisdicción, con fecha de 4 de enero de 1745 (Lorenzo, 1995: 296-307). 
Según señalaba el superintendente Cortés en diciembre de I744, para huir del reclutamiento para las obras de construcción, los indios se escondían en los bosques cercanos colocando "sus espías en los árboles y luego que descubren al cura o al juez ganan el bosque, y en esta materia no se puede poner castigo si no se le apremia a que se congreguen a estar en pueblos arreglados" (Lorenzo, 1995: 294).

A pesar de que el trabajo en la mina era muy pesado, los indios que podían ser contratados libremente preferían hacerlo en la minería, donde sus jornales alcanzaban los i7 pesos al mes, cifra muy superior a la que ganarían como albañiles (Lorenzo, 1995: 295). En las instrucciones para la puesta en marcha de las obras de construcción de la Villa se señalaba que los salarios debían ajustarse a lo que se ganaba en la ciudad de La Serena, adaptándose, eso sí, a los altos precios que vestuario y víveres alcanzaban en las zonas mineras (Lorenzo, 1995: 308).

En la declaración del superintendente, relativa a los indios huidos, llama la atención la referencia a utilizar los bosques como escondite y los árboles como atalaya desde la que divisar en altura la llegada de las autoridades civiles y eclesiásticas. Esto nos habla de la existencia de una vegetación, si no selvática, como indicaría la toponimia, si, al menos, mucho más frondosa que la que tiene en la actualidad. Había madera, por tanto, pero, probablemente, buena parte de ella perteneciera a los mineros que habían utilizado el método de denuncia para monopolizar el usufructo del bosque cercano a la mina. Es por esta razón que Manso de Velasco indicaba que se tomaran medidas destinadas a acabar de alguna manera con este monopolio. Así, señalaba que a pesar de que existía madera "con abundancia en el potrero que vulgarmente llaman El Grande y otros y los demás efectos en la vega del rio y demás parajes, a causa de impedir su corte los que son o se juzgan dueños de los potreros y los terrenos" (Lorenzo, 1995: 3II), las labores de construcción estaban detenidas por falta de madera, carrizo y paja y que, por tanto, para acabar con el problema era menester que se evitara el cerramiento para que:

(...) que los pobladores de la dicha villa puedan libremente cortar y sacar la madera que necesitaren para sus fábricas, así de el Potrero Grande como de los demás potreros y parajes en donde se halla, y también el carrizo, tome (sic), paja y demás materiales equivalentes, sin pagar al dueño cosa ni interés alguno, y solo con el cargo de que le avisen y no hagan daño (Lorenzo, 1995: 3II).

A pesar de estas instrucciones, la madera seguía escaseando como se evidencia en el hecho de que en 1775 se vio interrumpida la construcción de la torre de la iglesia por este motivo (Camus, 2004: 29I). Si no se obtenía madera para la torre de la 
Iglesia, podemos imaginar las dificultades para obtenerla en otras construcciones o menesteres. Esta intensificación del uso y del abuso perpetrado por los responsables de los cerramientos y de las denuncias se hizo aún más acuciante hacia I79I cuando las minas de plata superaban la docena (Torres Sánchez, 1985: 12).

De esta manera, el Valle se fue deforestando y con esto se redujeron las posibilidades de evasión y supervivencia de los naturales que se resistían a vivir congregados. En cierto modo, la presión de los enclosures hizo que se viera limitado el acceso a recursos y formas de vida alternativas a las marcadas por las leyes de indias en relación a la concentración en los pueblos de indios.

\section{El reparto de aguas}

Pero concentrados en el pueblo de indios, éstos tampoco tenían grandes posibilidades de supervivencia. Un nuevo revés les llegó con el reparto de mercedes de tierras a los españoles en la parte alta del río, muy cerca de donde se ubicaba el Pueblo de San Fernando. Su cacique, Francisco Taquía, reclamaba que el agua que se les había escamoteado "de la parte de arriba", donde tenían la mayor parte de la población, había sido usurpada por el corregidor "para chacras de algunas personas amigos suyos" (Sayago, I874: 311), cuestión que fue corroborada por un antiguo vecino de Copiapó, José Santander, quien el 7 de agosto dirigía una carta a Manso de Velasco indicando que las mejores tierras, las que tenían acceso a agua, se habían otorgado en la parte alta a individuos que ni tan siquiera pertenecían al grupo de antiguos pobladores a los que había que indemnizar (Lorenzo, I995: 312).

Con el fin de calmar los ánimos, el corregidor dictó al respecto medidas para que los vecinos propietarios de las chacras en la parte alta de la ciudad cuidaran el consumo a partir de la creación de norias y estanques con el fin de evitar el desabasto de la Villa. Todo ello bajo la advertencia de que, de lo contrario, dichas chacras serían relocalizadas en la parte baja (Sayago, I874: 255).

La demanda de agua seguía en ascenso y para procurar la equidad en el reparto se organizaron los primeros arreglos por turnos en 1757 para las haciendas de Bodega, perteneciente en aquel entonces al Convento de la Merced, y Chamonte, propiedad de Alonso Cisternas. En el valle arriba se estableció también un sistema de turnos semanal y el 20 de marzo de 1762 el corregidor José de Quevedo ordenó la supresión de cultivos de trigo, cebada y frijoles en grande y pequeña escala desde Potrero Grande hasta Punta Negra para evitar que el río llegara sin agua a la Villa $y$ al pueblo de indios. 
De todo esto es posible hacer seguimiento en el Boletín Municipal del Departamento de Copiapó, localizado en el Archivo del Museo Regional de Copiapó, donde se presenta la relación de establecimiento de turnos, incumplimientos y sanciones que se intentaron proyectar sobre los infractores antes del estallido del motín de I80I. Se trata de una larga nómina de conflictos que se sucedieron durante más de cuarenta años, si tomamos como fecha el establecimiento del primer turno organizado en 1757. En cuanto a la prohibición o limitación de la extensión de ciertos cultivos en determinados años críticos, hubo también varias disposiciones que quedan recogidas igualmente en el Boletín y que fueron también sistemáticamente incumplidas. Las sanciones iban desde multas a los usurpadores de agua hasta la quema de sementeras en las haciendas que desoían las ordenanzas. Pero estas prohibiciones no afectaban a los free rider, como Potrero Grande o Potrero Seco, quienes las incumplían sistemáticamente para sacar ventaja en producción frente a aquellos que sí cumplían, lo que les permitía, además, especular con precios y salarios.

De todas las disposiciones quizás la más firme fue la pronunciada por la Real Audiencia que autorizaba el I de junio de I79I a que el subdelegado Pinto y Cobos y el administrador de tabacos de la Real Hacienda, Juan Bautista Mastrana y Tranco, dictaran su plan de aguas, el que lleva fecha de 29 de octubre de 1792. Dicho plan fue realizado con todo el rigor de la ley, contando con las opiniones emitidas en sesiones de cabildo abierto de 27 de octubre con presencia tanto de las autoridades de la Villa como la del propio Pablo Tacquía. El acuerdo, tomado por consenso, fue enviado a la Real Audiencia para su aprobación, pero a juzgar por la seguidilla de denuncias posteriores, volvió a incumplirse nuevamente hasta colmar la paciencia de los afectados dando paso al denominado "motín de indios".

Debido a su inferioridad numérica el Pueblo de San Fernando no tenía más opciones que seguir apegándose a la ley y por ello, al iniciar el siglo xIx, el 2I de octubre de I8or, recurrió al procurador, José de Urrutia, a quien proveyó de un poder para representarlos ante el Cabildo y denunciar específicamente a los principales infractores: los cabildantes Manuel de la Torre (alguacil mayor) y Juan Bautista Sierralta (alcalde provincial), el primero como propietario de Potrero Grande y el segundo como dueño de trapiches al interior de dicha propiedad y como propietario de la Viñita, donde tenía plantadas "ciento y tantas fanegas de trigo" indebida del agua.

4 AHN, Real Audiencia (en adelante RA), vol. 2162, pieza 6I. 
Tenemos constancia de que Urrutia fue al Cabildo a presentar la denuncia y solicitar apoyo y no fue atendido 5 . La nueva falta de atención por parte de las autoridades fue la que provocó el motín pocos días después. Según el relato de Sayago, los indios de San Fernando, cansados del incumplimiento y la "despotiquez" con que actuaba el cabildo dominado por De la Torre y Sierralta, acordaron hacer justicia por su cuenta y el 9 de noviembre de I80I se presentaron ante las puertas de la casa capitular, encabezados por el cacique Taquia y el mandón Luis Normilla, y "con aceleradas voces y gritos, señalaron queremos agua y que toda baje de la hacienda de Potrero Grande o de lo contrario prenderemos fuego a las haciendas" (Sayago, 1874:263).

Los amotinados, que según las fuentes eran más de un centenar entre indios y españoles ${ }^{6}$, llegaron hasta las puertas del Cabildo armados de azadones y garrotes solicitando que corriera el agua o, de lo contrario, que les entregaran la cabeza de De la Torre. Ante la inminencia de un desastre, el cabildo autorizó a José Urrutia a llegar a Potrero Grande y dar la orden de que liberaran el agua que tenían retenida. Solo de esa manera se dispersó el tumulto evitándose que se desatara una verdadera contienda, puesto que, De la Torre - quien tenía fama de ser muy violento- contaba con el apoyo de su peonada e inquilinos que sobrepasaban la centena.

La violencia en la actitud de los propietarios de Potrero Grande se ve reflejada en el informe del subdelegado que siguió al tumulto, donde aparecen frecuentes declaraciones en las que queda claro que cuando se acercaba a supervisar que no hubiera plantaciones ilegales o retenciones de agua solía regresar con "recados satíricos, desvergonzados y de desafí" ${ }^{7}$. De la Torre y sus allegados son tildados de delincuentes y sus figuras aparecen definidas no como padres de república sino como padrastros (eran padres en el nombre, decía, pero no en las operaciones) pues "traían de cabeza a los tribunales y a la gente" y se veía venir desde hacía tiempo que podía ocurrir "un desastre irremediable". La fidelidad de peones e inquilinos la obtenía De la Torre por diversos medios, sin descartar la violencia, como queda relatado por los denunciantes en el juicio donde se señala que en varias ocasiones había sido denunciado y salido impune de maltrato a su peonada.

5 terior se habla de más de doscientos amotinados "vecinos y toda clase de gentes" (AHN,
RA, volumen 2162, f. 65) armadas que llegaron a pie y a caballo.

7 AHN, RA, volumen 2162, f. 68 .

8 AHN, RA, volumen 2162, f. 70 . 
El Subdelegado continuaba su descripción señalando:

Igualmente doy a entender la arrogancia con que La Torre entrampa las diligencias que se hacen saber y en el mismo indico la fantasía y es porque criminosa de este individuo, que en presencia del cura de esta villa y otras varias personas (.....) con despecho y absoluta resolución diciendo me daría un balazo, y por lo mismo expongo en el acápite subsecuente que estando a la vista las demostraciones insubordinadas de sus inquilinos y que no cumplen con lo que se les ordena, tenían por esto su plan formado en cometer cualquier atentado, supuesto que La Torre anteriormente ofrecido dos balas en el cuerpo al que fuera atrevido en quitarle la agua, y esto apoyo con lo mismo que estampo en el capítulo i7 del precitado informe donde copio a la letra lo que La Torre profirió, que había de sembrar aunque sea como se fuere y había de regar la hacienda. ${ }^{9}$

Tan acostumbrados estaban De la Torre y sus allegados a que su palabra y sus amenazas fueran la ley que todavía cuando llegaron los amotinados a la puerta del Cabildo fueron recibidos con arrogancia por parte de los cabildantes, entre los cuales se encontraba él mismo junto con Juan Bautista Sierralta. Al parecer la violencia no llegó a más porque intervino el vicario y se autorizó a Urrutia para que fuera a Potrero Grande a liberar las aguas retenidas.

De la Torre y Sierralta formaban parte de un grupo de mineros y hacendados coludidos para sacar el mayor provecho posible a la tierra, como ponen de manifiesto las declaraciones recogidas en el expediente del caso. De manera contundente, señalan en su alegación que las actividades mineras no podían sobrevivir sin el apoyo de la agricultura para mantener la peonada que trabajaba en sus minas e ingenios:

(...) necesitamos tener abastos cuantiosos de todo grano y al mismo tiempo cultivados pastos para la mantención de la mulada precisa como crecida para la conducción de abastos para minas, y de los productos de ellas a los trapiches ingenios y el de las leñas necesarias al consumo de estas máquinas y para otros menesteres anexos al ejercicio minero ${ }^{10}$.

Por tanto, naturalmente, implicaba contar con más agua que la que les pudiese corresponder tal y como ellos mismos alegaron en su defensa. Con esta y suce-

9

10 AHN, RA, volumen $2162, \mathrm{f} 6 \mathrm{I}$. 
sivas descripciones que se presentan a continuación podemos hacernos un claro esquema de lo que estaba ocurriendo en esas grandes propiedades, que se habían hecho autosuficientes a costa de extorsionar a las poblaciones autóctonas y a las que llegaron después.

Solo los negocios de De la Torre significaban 20 minas de oro, plata y cobre, aparte de las que manejaban sus hijos. Señalaba también que en los buitrones y trapiches ocupaban más de Ioo peones, $y$ que necesitaba mantener una tropilla de 200 mulas "que no pueden conservarse sin el pasto de alfalfa que es común y único en dichas haciendas, porque los cerros por la escasez de lluvias no permiten otros", labor en que se ocupaban 16 peones, los que debían alimentarse con "carne de Castilla y vaca". También señalaba que en sus propiedades había “algunas viñas, arboladas y otros plantíos de algodones e higueras que producen frutos precisos para al abasto minero, como para la peonada de los demás destinos y para los tejidos de lienzos para criados y familias" ${ }^{\prime 1}$. En su defensa, De la Torre argumentaba que, por ello, se les hacía necesario exceder la concesión establecida debido a las ocurrentes causas y pestes (...) sobrevenidos en casi todos los sembrados de este valle, sin cuyo acopio de dichos granos no puede subsistir el expresado giro de minas". En este punto, apelaba a los intereses de la Corona señalando que de otra manera no podrían realizar "el pago de créditos, así particulares como para el de cantidad de quintales de azogue que tenemos prontamente que satisfacer a la Real Administración de este ramo", señalando que el abastecimiento desde otras localidades era difícil, atendidas las largas distancias ${ }^{12}$.

A raíz de estas condiciones, solicitaba que se establecieran "los medios conducentes por cuyos conductos se nos facilite aquella porción de agua, que la urgencia de evitar aquel perecimiento, nos motiva a solicitar para el reparable cultivo de lo sembrado y plantado, que se lleva expuesto, en cuyos términos: a Vuestra Merced pedimos y suplicamos se digne darles aquel despacho, porque se haga asequible el uso de las aguas en los términos que se nos asigne en proporción del remedio para todo lo enunciado, que es merced que con justicia esperamos." ${ }^{13}$

En opinión del subdelegado, por el contrario, la actitud de absoluto desprecio por lo estipulado en cuanto a turnos de agua y extensión de las sementeras de los grandes propietarios como De la Torre, implicaba "los padecimientos de los infelices habitantes de esta jurisdicción; el notorio exterminio de los mineros; las hambrunas

11 AHN, RA, volumen, 2162, f. 6I.

12 AHN, RA, volumen, 2162, f. 6I.

13 AHN, RA, volumen, 2162, f. 6I. 
de los pobres pordioseros; $y$ las (muertes) continuas de estos por la suma necesidad y carestía de víveres; la universal mortandad de los pocos ganados que habían, como también de los animales de cabalgar"14.

Una vez sofocado el motín y ya puesto en conocimiento de las autoridades reales, la Real Audiencia por auto de II de febrero de 1802 dio plena autoridad a Juan de Dios Gatica para arreglar el asunto e instruir proceso contra los promotores del motín (Sayago, 1874ः 264). Por su parte, el Pueblo de Indios comisionó de nuevo a José Urrutia para que interpusiera una denuncia contra Sierralta y De la Torre ante la Real Audiencia. En esta ocasión, la estrategia defensiva de De la Torre y Sierralta fue procurar desacreditar a Urrutia alegando que no podía ejercer por ser mulato y, además, lo denunciaron acusándolo de vender cobre retobado en oro rico y oro bajo retobado en oro rico. No contentos con ello, lanzaron acusación de que era insolvente para pagar deudas contraídas e, incluso, de haber sustraído dinero de una tienda. De todas estas acusaciones Urrutia demostró su inocencia pero solo cuatro años después de haber sido designado para el cargo, lo que ralentizaba aún más el lento curso de la justicia. ${ }^{15}$ Finalmente, el fallo del 23 de Enero de I806, confirmó lo establecido en el plan de regadío de febrero de 1792 que señalaba que:

(...) desde la junta de los ríos hasta el lindero de Potrero Seco y Totoralillo, se asignan dos días, para que en ellos puedan usar únicamente del agua los habitantes y hacendados de aquel circuito. Desde Totoralillo hasta la Punta del Cobre y toma que llaman de los Arayas, otros dos días en la misma conformidad que los antecedentes. Desde la Punta del Cobre hasta la Punta Negra otros dos días, y un regador perenne hasta el Pueblo de Indios a más de sus días de turno, y el subdelegado que es o fuere, con los capitulares del cabildo, de acuerdo, nombrarían celadores, de la mejor conducta y probidad, para que sin contemplación ni disimulo, hagan la distribución decretada y cuiden de su puntual cumplimiento en lo sucesivo. ${ }^{16}$

El 27 de julio de 1807 fue publicada la cédula de Real Audiencia que daba por bueno el turno de aguas de Pinto y Cobos y Mastrana y al poco tiempo el subdelegado José Severino de Recabarren ordenó la quema de las sementeras que estuvieran ocupando aguas fuera de turno en la parte alta del valle. No obstante, una nueva estrategia de los propietarios vino a detener el curso de la justicia puesto que alegaron

AHN, RA, volumen, 2162, f. 6I.

15 AHN, Archivo Judicial de Copiapó (en adelante AJC), legajo 85.

16 AHN, AJC, legajo 85, legajo I3. 
tener dichas sementeras debido a que desconocían la existencia de una ley que lo prohibiera. Por tanto, se los convocó a lectura pública de dicha Cédula, cuestión que no se sancionó hasta el año de I8Io, diez años después que el conflicto, que se venía arrastrando desde hacía varias décadas, terminara en motín.

\section{Principios de diseño de los Ruc de Elinor Ostrom}

Con el fin de dar cuenta al objetivo principal de esta investigación, aplicaremos ahora la revisión de cada uno de los casos teniendo en cuenta los ocho principios de diseño planteados por Ostrom: existencia de unos límites claramente definidos; coherencia entre las reglas de apropiación y provisión con las condiciones locales; arreglos de elección colectiva; monitoreo; sanciones graduadas; mecanismos para la resolución de conflictos; reconocimiento mínimo de derechos de organización y organizan en múltiples niveles de instituciones anidadas de las actividades de apropiación, provisión, supervisión, aplicación de las normas, resolución de conflictos y gestión.

En el caso de la brea, vemos que no hubo cumplimiento en torno a la "claridad en el establecimiento de los límites" puesto que no se definió con precisión ni quiénes podían exactamente extraerla ni en qué lugares o cantidades. En un principio se otorgó el derecho de aprovechamiento a los indios, pero no se comunicó el lugar específico donde podrían proceder a la explotación. Posteriormente, se les reconoció el derecho al uso en el bredal de Potrero Grande pero después les fue denegado. En cuanto a la "coherencia" entre la explotación de la brea y las condiciones locales, no parece haber un incumplimiento de la lógica en el aprovechamiento de un recurso que se daba casi de forma natural en el Valle. El problema vino por los intereses de corregidores y propietarios en escamotear el acceso a los indígenas para sacar ventajas personales.

Durante el proceso, vemos que la única forma de "intervenir en los acuerdos y las modificaciones" fue a través de la justicia, sin la existencia de un diálogo previo abierto entre los diferentes usuarios potenciales. Por otra parte, la justicia actuó de manera inconexa al otorgar el derecho a la explotación y negar al mismo tiempo el acceso al lugar donde se producía.

El cuarto principio, el "monitoreo" por parte de los apropiadores, no se dio porque los vigilantes se designaron "desde arriba" y actuaron de manera corrupta dejando a las partes en el conflicto sin otra posibilidad de reclamo que la judicial. En ese sentido, si bien se cumple el quinto principio puesto que se "establecen sanciones", 
el cobro de las mismas no estaba asegurado ya que las personas responsables de aplicar la sanción eran las mismas que cometían la infracción.

Por otra parte, la conformación del sistema administrativo impedía el "acceso rápido y económico a instancias locales" para la resolución del conflicto. Los indios solo tenían posibilidad de apelar ante la Real Audiencia y se hacía a través del procurador, lo que ralentizaba y encarecía enormemente cualquier proceso. Las únicas instancias locales, los corregidores, actuaron abiertamente en contra de los intereses de los indios. En cuanto al séptimo principio, el "reconocimiento mínimo de derechos de organización", no se percibe que haya habido oposición a que los indios se organizaran para obtener lo que consideraban de justicia, más allá de que dicha organización pudiera o no ser efectiva.

En el caso del conflicto por el acceso a la madera, encontramos que las ordenanzas fueron dadas desde arriba, nuevamente, y que se marcaron pensando en la construcción de la Villa más que en el acceso común al recurso. En la práctica, no obstante, es evidente que las grandes propiedades se negaron a dar acceso libre y que la deforestación fue en aumento, lo que viene a poner en evidencia la inexistencia de sanciones y también la falta de coherencia entre las reglas de apropiación y las condiciones locales. No tenemos información relativa al monitoreo, pero el dato objetivo de la falta de madera para la Iglesia pone de manifiesto que ningún intento por hacer cumplir la ley, o por modificarla, fue eficaz.

En el decreto dado por Manso de Velasco se señalaba que serían los pobladores de la villa quienes tendrían acceso a dicha madera y de esa manera se les negaba a los habitantes del pueblo de indios. Esta disposición implicó claridad, aunque no coherencia ni con las condiciones locales ni con el espíritu que pretendía congregar también a los indios a vivir en comunidad ya que se les negaba la posibilidad de acceder a los recursos necesarios para construir en su pueblo. Sí se establecieron sanciones de hasta 200 pesos a quienes impidieran a los vecinos el acceso a la madera que serían utilizados en la construcción de la villa, una cantidad importante de dinero si tenemos en cuenta, por ejemplo, que los trabajadores de la mina, los mejor pagados con diferencia, obtenían I7 pesos mensuales. No obstante, no hemos tenido conocimiento de que alguna de estas sanciones se llegara a hacer efectiva.

El largo conflicto en torno a los turnos de riego es, sin duda, el mejor documentado de los tres y en el que observamos un mayor compromiso y precisión a favor de la definición de las reglas del juego. El primer principio, relacionado con los límites, está claramente definido a través del sistema de turnos. Se llega, incluso, a reglamentar la cantidad de tierras aptas para sembrar y los productos que debían suprimirse en momentos de crisis. No obstante, en ningún momento se mencionan 
limitaciones a la producción minera, salvo para señalar que el agua utilizada debía ser devuelta a su cauce. No obstante, sabemos que la estrecha vinculación existente entre agricultura-ganadería-minería establecía una relación directamente proporcional en el sentido de que un incremento en la producción minera exigía necesariamente un aumento de las actividades ganaderas y agrícolas para el sostenimiento de mulas y peones, lo que implicaba, necesariamente, un mayor consumo de agua.

Tampoco se cumple, consecuentemente, el principio dos que establece que debe haber cohesión entre los recursos explotados y las condiciones locales. La sobrexplotación minera demandaba un consumo intensivo de agua y madera que perjudicaba al resto de los habitantes del valle y que amenazaba el equilibrio ambiental de la zona. La deforestación fue una consecuencia lógica, y con ella los aluviones y las sequías que forman parte de la vida cotidiana del Valle en la actualidad.

En relación a la toma de decisiones de manera colectiva, hay que señalar que las aguas turnales comenzaron a organizarse por autoridades, pero una vez constituido el Cabildo (del que formaban parte algunos de los principales involucrados), empezó a sesionar y reglamentar al respecto. En estas reuniones no tomaba parte el resto de la comunidad más que en ocasiones contadas cuando se convocaba a cabildo abierto. Otras veces, el consenso tuvo que ser forzado, como en el caso que nos ocupa, donde fue la población amotinada la que obligó al Cabildo a tomar la decisión de cortar el acceso al agua a Potrero Grande a golpe de campana, lo que resonó más como una amenaza que como una llamada a la concordia.

También se establecieron sanciones y monitoreo. Las sanciones llegaron a ejercerse, incluso, de forma violenta con la quema de las sementeras ilegales. El problema radicaba, no obstante, en que las exiguas fuerzas de los vigilantes nada tenían que hacer frente a la violencia ejercida y las amenazas proferidas por los propietarios o sus capataces.

Si bien existía el mecanismo de organización de la población para exigir sus derechos o para cuestionar a los infractores por medio del uso de la ley a través de la intermediación del procurador general y el protector de indios, la única forma de encontrar respuesta era por vía judicial apelando a la Real Audiencia, lo que ralentizaba y encarecía los procesos.

\section{Conclusiones}

Para finalizar, nos permitimos hacer una reflexión general alrededor de los tres casos mencionados. En ellos no se contempló el principio número 8 porque no aplica 
debido a que el sistema de explotación de recursos en el Valle de Copiapó no quedaba sumido en otros niveles superiores para cada uno de los casos. No obstante, si bien no es posible hablar de niveles superiores específicos en cuanto a regadío o explotación de productos como la brea o la madera, si podemos hablar de una institucionalidad mayor de carácter general que los amparaba. En torno a la explotación de recursos comunes, existía una legislación y una serie de mecanismos judiciales y de cargos públicos para la supervisión y control del cumplimiento de leyes y disposiciones. Los sistemas turnales y las resoluciones favorables a la explotación de la brea o al acceso a la madera, jugaban a favor del mantenimiento de los comunales.

Sin embargo, estas mismas instituciones, al no poner límites a la producción minera y a su utilización de recursos como el agua y la madera, ampararon finalmente a los grandes propietarios en tanto prevalecieron los intereses de éstos por sobre los de los demás pobladores del Valle. Es evidente que en los conflictos aquí analizados siempre hay un beneficiario absoluto: Potrero Grande (primero en manos de los Cisternas y luego de los De la Torre) -si bien no fue el único gran propietario que se enseñorea de las tierras y los recursos más allá de lo legal y por medio del uso de la fuerza-, y con él la minería asociada a la agricultura y la ganadería orientadas todas ellas a la producción de minerales preciosos.

Agrupaciones como la organizada por De la Torre y Sierralta, tenían asegurado un lugar de privilegio en la toma de decisiones por formar parte del cabildo y, cuando esto no era suficiente para sus fines, no dudaban en utilizar la amenaza y el uso de la fuerza contra sus opositores, que no eran pocos, aunque sí más débiles. Es por ello que el subdelegado los señalaba como "padrastros de república" puesto que desde la institucionalidad estaban operando en beneficio propio sin preocuparse por el perjuicio ajeno. No solo monopolizaban las instancias de toma de decisiones sino que utilizaban todas las triquiñuelas judiciales para que las demandas se eternizaran.

Las Leyes de Indias propendían a la protección de los recursos comunes. No obstante, el gobierno se mostró incapaz de asegurar el cumplimiento de las mismas y ofreció multitud de posibilidades a quienes infringían la ley para ralentizar los procesos legales y obtener puestos de responsabilidad en la toma de decisiones. Los mayores ingresos a la Corona provenían, sin duda, de la minería y por esto fueron los "niños mimados" del sistema, lo que les permitió salir beneficiados en incontables ocasiones. En otras palabras, los mecanismos ideados para evitar o solucionar los conflictos fueron, constantemente, ignorados por los responsables de su buen funcionamiento en aras de privilegiar a los sectores económicos que resultaban más rentables. El uso de la fuerza, sustituyó, con frecuencia, a las instituciones que 
fueron, sistemáticamente, ignoradas por corregidores, encomenderos y hacendados, como hemos visto en los casos aquí analizados.

Las comunidades, por su parte, no vivieron el proceso cruzadas de brazos, sino que ofrecieron resistencia de muy variada índole. Violencia, evasión y procesos judiciales fueron los mecanismos de resistencia empleados en los casos aquí tratados. En ocasiones, los agraviados llegaron a unir sus intereses, como en el caso del motín, en el que participaron tanto los habitantes del Pueblo de Indios como los de la Villa. A pesar de ello, los intereses de la minería y la agricultura y ganadería a ella asociada prevalecieron sobre los del resto de los habitantes del Valle.

Con la Independencia y los nuevos derroteros de la política nacional chilena, las grandes haciendas (muchas de las cuales contaban en su interior con explotaciones mineras y/o trapiches) sufrieron cambio de manos. Tenemos el caso de Potrero Seco que, según cuenta Darwin en 1835, había sido adquirida por una sociedad de comerciantes británicos. No obstante, el cambio de manos, su principal producción seguía siendo el trébol de la zona (alfalfa) para el pastoreo de las mulas. A pesar de lo extraño que pudiera resultar, señala que la producción de la mina depende absolutamente de la producción de forraje para las mulas ocupadas del laboreo y parte del transporte. Aun siendo el negocio de la sociedad de Potrero Seco la explotación de cobre, nada ganaría si no pudiera transportarlo hasta el puerto (Darwin, 2011:59).

La minería y la agricultura iban, entonces, de la mano y no es por ello posible hablar de un conflicto entre agricultores y mineros pues la relación no es de ninguna manera tan dicotómica como se viene presentando desde entonces, sino que, en ocasiones, los mismos actores se dedican a ambas actividades o establecen sociedades entre ellos. Lo que pasaba en Copiapó, antes y después de la Independencia, es similar a lo que ocurría durante la colonia en Tarapacá donde como señala Sergio Villalobos, la alfalfa era el cultivo que más se desarrollaba en las quebradas por lo que estaba presente en la mayoría de las propiedades agrícolas, así como en algunos sitios urbanos e, incluso, en molinos, donde era explotada y recolectada de manera sistemática para su mejor aprovechamiento como forraje para las mulas utilizadas en las labores y transporte de la producción minera (Villalobos, 1979: 109).

La sobrexplotación de los bosques llevó a la deforestación del Valle y el agua del río Copiapó sigue siendo la protagonista de la conflictividad existente entre la población en general, los agricultores y los mineros. Estos últimos grupos siguen culpándose unos a otros por la deforestación y la falta de agua como en el siglo XIx y la consecuencia de todo esto es que el agua que llega a la ciudad carece de las mínimas condiciones para ser consumida sin atentar contra la salud. El lecho del río aparece permanentemente sin una gota de agua y plagado de basura y escombros 
procedentes de las viviendas que se construyen contra toda lógica en su cauce. De esta manera, cuando se producen precipitaciones abundantes en la cordillera, el deshielo produce grandes avenidas de agua que anegan las poblaciones con consecuencias catastróficas como las vividas recientemente en Copiapó y Tierra Amarilla.

\section{Fuentes}

Archivo Histórico Nacional (AHN), Archivo Judicial de Copiapó, legajo 85

AHN, Notarios de Copiapó, vol.I

AHN, Real Audiencia, vol. 2162.

\section{Bibliografía}

Boletin Municipal del Departamento de Copiapó. Recopilación de las Leyes, Ordenanzas, Reglamentos, Disposiciones de Policía, etc. (1871), Santiago, Imprenta de la República.

Broll, J. (1988), "La fundación de una villa en el Norte Chico: San Francisco de la Selva de Copiapó”, en: Broll, J. y Pinto J. (eds.), Copiapó en el siglo XVIII, Valparaíso, Universidad de Valparaíso, pp. 42-IO2.

Camus, Pablo (2004), "Los bosques y la minería del Norte Chico, siglo xix. Un mito en la representación del paisaje chileno", Historia, 37, pp. 289-310.

Carlos ir (168I) Recopilación de las Leyes de los Reynos de las Indias (I68I), Madrid, por Julián de Paredes.

Darwin, Charles (20II), Viaje de Valparaíso a Copiapó, Valparaíso, Editorial Universitaria.

Lorenzo, L. (Comp.) (1995) Fuentes para la historia urbana del Reino de Chile, t. I, Santiago, Academia Chilena de la Historia.

Ostrom, Elinor (20II), El gobierno de los comunes. La evolución de las instituciones de acción colectiva, México, Fondo de Cultura Económica.

Sayago, Carlos María (1874), Historia de Copiapó, Copiapó, Norte Grande Ediciones.

Torres Sánchez, J. (1985), "Los conflictos de agua del Valle de Copiapó en el siglo xvirI", Nueva Historia, 13-I4, pp. 3-105.

Villagrán, Carolina y Victoria Castro (2003), Ciencia indígena en los Andes del Norte de Chile, Santiago, Editorial Universitaria. 
Villalobos, Sergio (1979), La Economía de un desierto. Tarapacá durante la Colonia, Santiago, Ediciones Nueva Universidad.

INMACULAda Simón Ruiz

Es doctora en Geografía e Historia por la Universidad Complutense de Madrid. Directora del Instituto de Estudios Sociales y Humanísticos (Idesh) y profesora titular de la Universidad Autónoma de Chile. Investigadora asociada del Instituto de Estudios Latinoamericanos (Lelat) de la Universidad de Alcalá. Ha sido Investigadora I 3 p de la Escuela de Estudios Hispanoamericanos del Consejo Superior de Investigaciones Científicas (CSIC) de España, e investigadora principal del proyecto Regular del Fondo Nacional de Desarrollo Científico y Tecnológico, Fondecyt, de Chile, financiado por la Comisión Nacional de Investigación Científica y Tecnológica (Conicyt) del gobierno de Chile:"Transformaciones políticas y socio-ambientales derivadas del cambio en el paradigma higiénico sanitario. Modernización del sistema de aguas en chile a finales del siglo xıx: los casos de Valparaíso y Talca”. Tiene diversas publicaciones sobre gestión del agua y conflictos en Chile y en México en la transición del siglo xix al xx.

Raúl Sánchez Andaur

Profesor de Estado en Historia y Geografía y doctor en Historia por la Universidad de Chile. Profesor titular de la Universidad Autónoma de Chile, asociado al Instituto de Estudios Sociales para el Fomento y Desarrollo de Hispanoamérica. Ha sido coinvestigador en los Proyectos del Fondo Nacional de Desarrollo Científico y Tecnológico, Fondecyt, “Transformaciones políticas y socio-ambientales derivadas del cambio en el paradigma higiénico sanitario. Modernización del sistema de aguas en chile a finales del siglo xix: los casos de Valparaíso y Talca" y "Minería e industrialización: la economía nortina y los inicios de la industria nacional (1850I914)". Tiene publicaciones sobre historia colonial de Chile y sobre gestión del agua en Chile, siglos XIX y Xx.

Citar como: Inmaculada Simón Ruiz y Raúl Sánchez Andaur (2018), “Violencia, transgresión y bienes comunes en Copiapó (siglos xvir y XVIII)", Iztapalapa. Revista de Ciencias Sociales y Humanidades, núm. 85, año 39, julio-diciembre de 2018, ISSN: 2007-9176; pp. II-32. Disponible en <http:// revistaiztapalapa.izt.uam.mx/index.php/izt/issue/archive > . 